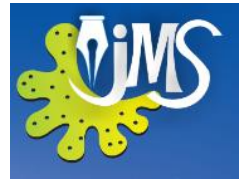

\title{
Analysis of Severity and Anatomical Distribution of Diabetic Foot Ulcers; A Single Unit Experience
}

\author{
${ }^{1} \mathrm{~A}$ L A M C Ambegoda, ${ }^{1} \mathrm{~J}$ R Wijesekera, ${ }^{1} \mathrm{~K}$ I Panditharathne, ${ }^{1} \mathrm{R}$ T Gamage, \\ ${ }^{1} \mathrm{O}$ M D C S Mudalige and ${ }^{2}$ M D R M Piyasiri \\ ${ }^{1}$ Colombo North Teaching Hospital, Ragama, Sri Lanka \\ ${ }^{2}$ Base Hospital, Dambadeniya, Sri Lanka
}

\begin{abstract}
Diabetes is the commonest cause of foot ulceration in developing countries leading to severe morbidity and mortality. The main aim of this study was to assess anatomical distribution of diabetic foot lesions, categorize it according to Wagner wound grading, find any association between smoking packs years and the severity of the foot lesions. Also to assess the relationship between the bony deformities and anatomical distribution of the ulcers. This was a cross sectional descriptive study conducted in a casualty surgical unit in a tertiary care teaching hospital for a period of 4 months. 91 diabetic patients with a diabetes related foot lesion were enrolled after simple randomization. Pretested interviewer administered questionnaire was used to gather data. Variety of soft tissue and bony changes of diabetic foot were assessed. Lesions were classified according to Wagner classification. Data was analysed using Epidata software. From the 91 participants, 55 (61\%) were males and 36 (39\%) females. Mean age was at 60. $12 \pm 10.19$ years. Median diabetes duration was 10 years (Interquartile range $=4.25-16.75$ ). Wagner grade 1, 2, 3, 4 and 5 were $17.7 \%, 40.65 \%, 28.8 \%, 13.3 \%$ and $0 \%$ respectively. Commonest ulcer location was margins of foot (31.87\%). There was no statistically significant association between the pack years of cigarette smoking males and severity of foot lesions (Spearman's rank correlation coefficient $=-0.037, p=0.82$ ). Patients with claw and hammer toe deformities had their ulcers located in fingertips and toes $(p=0.0185)$. But there was no statistically significant association with flat foot deformity and ulcer distribution on any particular anatomical area in the foot $(p=0.0511)$. In conclusion there is a statistically significant association between toe deformities and ulcer occurrence in finger tips. No significant correlation between severity of smoking and severity of foot lesions among males is present.
\end{abstract}

KEYWORDS: Diabetic ulcers, Diabetic foot lesions, Wagner classification, Dlcer distribution 


\section{INTRODUCTION}

The burden of diabetes is increasing globally, particularly in developing countries including Sri Lanka according to World Health Organisation. Disease prevalence is alarmingly high as one in five adults has either diabetes or pre diabetes and one third of them are undiagnosed (Katulandaet al., 2008). Diabetes is thriving in epidemic proportions, which is quite evident when comparing with the disease prevalence in early nineties in rural populations which was as little as $2.5 \%$ (Katulanda et al., 2006). It is also the commonest cause of foot ulceration in the country according to a hospital based study carried out two decades ago (Fernando, 1996).

Foot ulceration occurs due to interplay of several complex factors in long standing diabetes mellitus. Microangiopathy is unique to diabetes where tissue diffusion is impaired, mainly in the arterioles. It is asymptomatic in $50 \%$ of the patients, largely due to the presence of sensory neuropathy (Kannel 1994; Hiatt, 2001). Neuropathy is caused by either neuronal ischemia or necrosis due to the exposure of toxic metabolites. Sensory neuropathy causes unawareness of protective foot sensation to pain, temperature and joint proprioception (Levy \& Valabhji, 2008).

Motor weakness causes abnormal weight distribution in foot. This results in foot deformity and callosity formation according to Ulbrecht, et al. (2004). Autonomic neuropathy causes poor blood flow regulation and increased osteoclast activity in bones. This predisposes the foot for pathological fractures and subsequent anatomical foot deformities, known as Charcot foot. Dry and stiff skin ensues due to reduced sweat production. Increase predisposition to infection is mainly due to dysfunctional neutrophils. Loss of protective skin sensation causes injuries at sites of high plantar pressure. Microorganisms can enter through these injuries. Most amputations result from infection, ischemia or both, complicating a neuropathic ulcer (Levy et al., 2008). It is found that higher ulcer risk is associated with hammer or claw toe deformity. According to multivariate models factors affecting foot ulcerations are diabetes duration, diabetes type, race, smoking status, diabetes education, joint mobility, hallux blood pressure and other foot deformities (Boyko et al., 1999). Relationship between ulcer location and bony deformity has been extensively studied. Presence of charcot feet causes ulceration in the midfoot as pes planus is commonly associated with it. Toe deformities such as claw toe, hammer toe, hallux rigidus causes ulcers predominantly in the forefoot (Mueller et al., 1990; Ledoux et al., 2005).

Presence of bony deformity increases the patients risk for further ulceration and amputation. Therefore prompt identification should be followed by an early referral to a specialist. Wearing the correct footwear and careful removal of callosities is important. Corrective surgery should be undertaken as a final option (Singh et al., 2005).

A comparative study done in Sri Lanka reveals several factors affecting foot ulceration in the local population such as male sex, poor education level, poor income, usage of slippers instead of covered shoes or sandals, presence of callosity and foot deformities (Shriyani et al., 2013). Peripheral neuropathy is common among newly diagnosed diabetic patients, accounting for $9.8 \%$. Foot ulceration is the presenting symptom of $2.6 \%$ newly diagnosed diabetic patients. Reason for this is attributed to genetic predisposition and delay in diagnosis of diabetes in Sri Lanka (Weerasuriya et al., 1998).

Polymicrobial infection of diabetic foot ulcer is a major reason for delayed ulcer healing. A local study on ulcer bacteriology reveals Pseudomonas spp, Escherichia coli, Staphylocccus spp and Acenotobacter spp are responsible in descending order of prevalence. $40 \%$ of Staphylococcal infections are MRSA 
positive which is on par with rest of the world (Senanayake et al., 2013).

According to emedicine, Cigarette smoking is a major risk factor in foot ulceration. It further impairs the already compromised blood supply to the foot by its main component Nicotin, a potent vasoconstrictor. This expedites nerve damage due to obliteration of vasa nervorum in neural tissue. Cigarette smoke contains substances which impairs immunity. As a result foot sepsis takes place rapidly.

A descriptive cross sectional study done in the National Hospital OF Sri Lanka, among patients with diabetic foot ulcer has revealed satisfactory knowledge regarding principles of foot ulcer care. But unfortunately compliance to such principles found to be extremely poor (Jinadasa \& Jeewantha, 2011). As a result, Sri Lankan diabetes patients are more prone for foot ulceration and its complications.

The cost that the government has to incur for these patients is colossal. $4.3 \%$ of total hospital admissions consist of patients with complications related to diabetic foot ulcers. Mean hospital stay is 10.9 days. $61.8 \%$ patients get ulcers following preventable minor trauma. Therefore, proper foot care practices can reduce government expenditure on diabetic patients (Siriwardana \& Weerasekera, 2009).

Although many local surveys are available in literature analyzing various aspects of diabetic foot ulcer disease, studies on anatomical distribution of foot lesions remains sparse. Few studies are available with proper categorization of foot lesions according to a standard wound classification system. Variation between ulcer severity and smoking pack years has not been studied extensively. How the presence bony deformity affects the anatomical ulcer location has to be established. The principle aim of this descriptive cross sectional study is to find answers to above questions.
University of Texas (UT) wound classification and Wagner wound classification systems are two commonly used ulcer classification systems. Both classifications are easy to use and provide a guide to plan treatment strategies. Although both systems focus on wound depth, UT classification distinctively uses degree of ischaemia in to the account. UT classification is more descriptive and shows a greater association with increased risk of amputation and prediction of ulcer healing when compared with the Wagner system (Oyibo et al., 2001)

But for the accurate analysis using UT classification, it requires correct diagnosis of ischaemia and infection. Although infection can be easily assessed clinically by the presence of systemic features and acute inflammation around the lesion, accurate clinical diagnosis of ischaemia is difficult at least without a hand held doppler which is not commonly available in a resource poor government sector setting.

Therefore, Wagner classification is a better option to use in a resource poor setting. Since the assessment of outcomes such as amputation risk and wound healing is not the main purpose of this study, usage of Wagner classification is acceptable.

\section{METHODOLOGY}

This was a descriptive cross sectional study carried out in a surgical casualty unit at Colombo North Teaching Hospital. Study population consisted of diabetic patients (both type 1 and 2) with a diabetes related foot lesion. Diagnosis of diabetes was confirmed after reviewing past medical records and investigations i.e clinic records, diagnosis cards ect.

Chronic diabetic ulcers, acute infected ulcers, deep foot abscesses and gangrenous lesions situated below bilateral malleolar level were considered as diabetic foot lesions. 
Diabetic patients admitting with acute traumatic wounds were excluded from the study.

All the casualty admissions fulfilling the above criteria were enrolled following simple randomization. Ninety one patients were selected for a period of 4 months, from October 2014. Informed written consent was obtained from all the participants.

Data collection was done with the aid of a pretested interviewer administered questionnaire during patients' stay in the ward. It comprised of information on demographics (age, sex) duration of diabetes, duration of present lesion, history of previous ulcers, smoking pack years and alchohol intake. All foots were assessed by the principle investigator with regard to soft tissue changes such as acute inflammation, callus formation, presence of distal pulse and anatomical location of the lesion. Bony changes such as claw toe, hammer toe, flat foot and rocker bottom feet were also assessed.

Foot lesions were graded according to Meggit Wagner wound classification (Wagner, 1981).

Grade 1 :- Superficial (Epidermal)

Grade 2 :- Extending to dermis, subcutaneous fat, deep fascia, exposing tendons, joint capsules, without abscess or osteomyelitis

Grade 3 :- Deep ulcer with abscess, osteomyelitis or septic arthritis

Grade 4 :- Localized gangrene i.e. Forefoot, heel or fingers

Grade 5 :- Extensive gangrene of foot

All the foot lesions were categorized according to above grading system. Deep abscesses and unhealthy ulcers were assessed under anesthesia at the time of surgical debridement. Wound depth was assessed using a sterile blunt probe. Osteomyelitis was detected by $\mathrm{X}$ ray evidence if the bone can be probed or palpable during debridement (Grayson et al., 1995).
In patients with multiple or bilateral lesions, lesion with highest Wagner grade was assessed. If more wounds with similar Wagner grading was present, ulcer with the biggest diameter was considered for data analysis.

Soft tissue infection was diagnosed clinically by the presence of acute inflammation such as foot pain, erythema, pitting edema, warmth and tenderness. Pulse rate and temperature was assessed in general examination. Dorsalis pedis and posterior tibial pulses were assessed clinically. Pre ulcerative lesions like blister formation and callosities were recorded.

Location of the lesion was categorised in the Questionnaire according to different anatomical regions of the foot. Lesions which overlapped more than one anatomical location were counted in both locations.

Data analysis was done using Epidata software. Since there was skewness in the distribution of data, most of the statistical analyses were done using non parametric tests to increase the accuracy of results. Statistical significance was assessed using chi square test and Spearman's rank correlation coefficient.

\section{RESULTS}

From the 91 participants, there were 55 males $(61 \%)$ and 36 females (39\%). The mean age was $60.12 \pm 10.19$ years, ranging from 29 to 89 years. Median diabetes duration at the time of admission was 10 years; interquartile range (IQR) between 4.25 and 16.75. 38 were either active smokers or ex-smokers. None of the females were smokers. Therefore, out of 55 males $69.09 \%$ were smokers. Median smoking pack years was $5(\mathrm{IQR}=1.55-10.55)$. Alcohol consumption was observed exclusively among males $(n=41,74.56 \%)$.

Twenty seven patients had (30\%) noticed their foot ulcer began as a blister. Thirteen patients (14.28\%) had callosity 
formation in the plantar aspect. Seventy three patients had swollen foot associated with their foot lesion $(80 \%)$. Lesions were painful in 64 patients $(70 \%)$.

On examination, 39 patients were having clinically significant pitting edema around medial malleolus (43.3\%). Erythema of the foot was present in 53 patients $(58.8 \%)$. In comparison with the contralateral non affected foot, warmth was evident in the affected foot in 63 patients $(68.8 \%)$.Worse the ulcer grading, more men tend to get affected.

73 patients were having $(80.0 \%)$ palpable distal foot pulses; either dorsalis pedis, posterior tibial or both. In 13 patients $(14.4 \%)$ pulses were not palpable due to severe pedal edema. Pulses were obviously not palpable in 5 patients $(5.5 \%)$.

According to table 1, Wagner grade 2 was the commonest presentation $(40.6 \%)$ whereas none were having grade 5 lesions. Worse the ulcer grading, more men tend to get affected.

Table 1. Wagner grading and demographics

\begin{tabular}{|l|l|l|l|}
\hline Grade & $\mathbf{n}$ & $\begin{array}{l}\text { Mean age } \pm \\
\text { SD (y) }\end{array}$ & $\begin{array}{l}\% \text { of } \\
\text { men }\end{array}$ \\
\hline Wagner 1 & $16(17.7 \%)$ & $53.37 \pm 12.17$ & $50.0 \%$ \\
\hline Wagner 2 & $37(40.6 \%)$ & $60.75 \pm 8.9$ & $56.75 \%$ \\
\hline Wagner 3 & $26(28.8 \%)$ & $63.30 \pm 9.6$ & $61.55 \%$ \\
\hline Wagner 4 & $12(13.3 \%)$ & $60.33 \pm 7.43$ & $83.33 \%$ \\
\hline Wagner 5 & 0 & 0 & 0 \\
\hline
\end{tabular}

$\mathrm{y}=$ years, $\mathrm{SD}=$ Standard deviation

Wagner grade 3 patients had the highest median duration of diabetes mellitus whereas Wagner 4 had the shortest. The median duration of the lesion before admitting to the hospital was 2 weeks except for Wagner grade 3 lesions, which was 5 weeks (see table 2).
Table 2. Wagner grading and diabetic duration, duration of lesion

\begin{tabular}{|l|l|l|l|l|}
\hline Grade & $\begin{array}{l}\text { Median } \\
\text { duratio } \\
\text { n of } \\
\text { Diabetes } \\
(\mathbf{y})\end{array}$ & $\begin{array}{l}\text { IQR = Q1 } \\
-\mathbf{Q 3}\end{array}$ & $\begin{array}{l}\text { Median } \\
\text { duration } \\
\text { of lesion } \\
(\mathbf{w})\end{array}$ & $\begin{array}{l}\mathbf{I Q R}=\mathbf{Q 1} \\
-\mathbf{Q 3}\end{array}$ \\
\hline Wagner 1 & 9.5 & $2.0-12.75$ & 2.0 & $1.0-4.0$ \\
\hline Wagner 2 & 10.0 & $1.75-20.0$ & 2.0 & $2.0-5.0$ \\
\hline Wagner 3 & 15.0 & $8.5-20.0$ & 5.0 & $2.25-12.0$ \\
\hline Wagner 4 & 8.5 & $4.75-12.0$ & 2.0 & $1.0-2.0$ \\
\hline Wagner 5 & 0 & 0 & 0 & 0 \\
\hline
\end{tabular}

$\mathrm{y}=$ years, $\mathrm{w}=$ weeks, IQR $=$ Interquartile range

Table 3. Location of the lesion and frequency

\begin{tabular}{|l|l|}
\hline Location & n \\
\hline $\begin{array}{l}\text { Margins of the foot including heel } \\
\text { and fingertip margins }\end{array}$ & $29(31.87 \%)$ \\
\hline Big toe including its margins & $22(24.4 \%)$ \\
\hline Heel including its margin & $21(23.34 \%)$ \\
\hline $\begin{array}{l}\text { Lesions extending to dorsal aspect } \\
\text { from plantar aspect }\end{array}$ & $19(21.15 \%)$ \\
\hline $\begin{array}{l}\text { Other fingers including its } \\
\text { margins }\end{array}$ & $15(16.48 \%)$ \\
\hline Other metatarsal heads & $10(11.1 \%)$ \\
\hline First metatarsal head & $9(10.1 \%)$ \\
\hline Not falling to above regions & $5(5.49 \%)$ \\
\hline
\end{tabular}

The commonest location for foot lesions was the margin of the foot. As seen in table 3, heel was the commonest pressure point. Prevalence of ulcers in the pressure points i.e. heel, metatarsal heads was $43.95 \%(n=40)$.

According to table 4, the median diabetic duration was significantly less in patients without any bony deformity than patients who were having a bony deformity.

Table 4. Wagner grading and foot deformities

\begin{tabular}{|l|l|l|l|}
\hline & $\mathbf{n}$ & \multicolumn{2}{|l|}{ Diabetes duration (y) } \\
\cline { 3 - 4 } & & $\begin{array}{l}\text { Median } \\
(\mathbf{y})\end{array}$ & $\mathbf{I Q R}=\mathbf{Q 1}-\mathbf{Q 3}$ \\
\hline $\begin{array}{l}\text { Claw + } \\
\text { Hammer toe }\end{array}$ & $47(51.64 \%)$ & 15.0 & $7.25-20.0$ \\
\hline $\begin{array}{l}\text { Flat feet }+ \\
\text { Rocker bottom } \\
\text { feet }\end{array}$ & $18(19.78 \%)$ & 15.0 & $7.75-20.0$ \\
\hline $\begin{array}{l}\text { No bony } \\
\text { deformity }\end{array}$ & $26(28.57 \%)$ & 10.0 & $3.0-15.0$ \\
\hline
\end{tabular}


Most of the cigarette smoking males were having Wagner grade 3 lesions as seen in table 5. But there was no statistically significant correlation between the number of pack years and severity of the ulcer grading in the smoking population, according to Spearman's rank coefficient $(\mathrm{R}=-0.037, p=0.82)$.

Table 5. Wagner grading and smoking pack years among male population

\begin{tabular}{|l|l|l|l|}
\hline Grading & $\begin{array}{l}\text { Number } \\
\text { of } \\
\text { cigarette } \\
\text { smoking } \\
\text { males } \\
(\mathbf{n = 3 5})\end{array}$ & $\begin{array}{l}\text { Median } \\
\text { smoking pack } \\
\text { years among } \\
\text { cigarette } \\
\text { smoking males }\end{array}$ & IQR = Q1 - Q3 \\
\hline Wagner 1 & 4 & 5.0 & $1.8-10.5$ \\
\hline Wagner 2 & 11 & 4.5 & $1.52-11.25$ \\
\hline Wagner 3 & 17 & 5.0 & $1.6-12.0$ \\
\hline Wagner 4 & 6 & 5.0 & $1.55-10.5$ \\
\hline Wagner 5 & 0 & 0 & 0 \\
\hline
\end{tabular}

$\mathrm{IQR}=$ Interquartile range

As seen in table 6, claw toe and hammer toe deformities were significantly associated with lesions occurring in fingertips of the foot than other regions of the foot ( $p=$ 0.0185). Patients who were having flat foot and rocker bottom deformity had ulcers in the margins of the foot and the big toe than any other parts of the foot, although this association was not statistically significant $(p=0.0511)$.

Table 6. Bony deformity and location of the lesion

\begin{tabular}{|l|l|l|}
\hline Location & $\begin{array}{l}\text { Claw toe + } \\
\text { Hammer } \\
\text { toe } \\
(\mathbf{n}=\mathbf{4 7})\end{array}$ & $\begin{array}{l}\text { Flat foot + } \\
\text { Rocker bottom } \\
\text { feet (n = 18) }\end{array}$ \\
\hline $\begin{array}{l}\text { Margins of the foot } \\
\text { including heel and } \\
\text { fingertip margins }\end{array}$ & 14 & 5 \\
\hline $\begin{array}{l}\text { Big toe including its } \\
\text { margins }\end{array}$ & 8 & 6 \\
\hline $\begin{array}{l}\text { Other fingers including } \\
\text { its margins }\end{array}$ & 5 & 2 \\
\hline First metatarsal head & 3 & 0 \\
\hline Other metatarsal heads & 5 & 1 \\
\hline Heel including its margin & 6 & 1 \\
\hline $\begin{array}{l}\text { Lesions extending to } \\
\text { dorsal aspect from plantar } \\
\text { aspect }\end{array}$ & 4 & 2 \\
\hline $\begin{array}{l}\text { Not falling to above } \\
\text { regions }\end{array}$ & 2 & 1 \\
\hline$p$ value & 0.0185 & 0.0511 \\
\hline
\end{tabular}

Fifteen patients had undergone single or multiple toe amputations $(16.48 \%)$ before current admission. There were 5 patients each who had undergone below knee or above knee lower limb amputations (5.5\%). Only 2 patients were found to be having forefoot amputation $(2.2 \%)$.

\section{DISCUSSION}

The main aim of this study was to assess anatomical distribution of diabetic foot lesions and categorize it according to Wagner wound grading. Secondly, to find the association between smoking pack years and the severity of the foot lesions among the male population. Association between the bony deformities and anatomical location of the ulcer was also assessed.

Males (61\%) had a statistically significant number of diabetic foot lesions than females $(39 \%)\left(\chi^{2}=4.92, p=0.026\right)$. This trend was observed in many surveys done locally and overseas (Oyibo et al., 2001; Armstrong, et al., 1998; Beckert et al., 2006; Leese et al., 2007). Although the reason for this is incompletely understood, studies have revealed males are more prone to get a severe form of neuropathy than females (Dinh et al., 2008). Neuropathy is one of the main causes for diabetic foot ulceration along with other important local factors such as bony deformities, vascular insufficiency, callosity formation, foot trauma and failure to use proper footwear (Levy \& Valabhji, 2008).

Wagner grade 2 was the commonest presentation $(40.6 \%)$ whereas none had grade 5 lesions which indicate extensive gangrene of foot (Table 1). Wagner 3 and 4 lesions indicate deep infection and localized gangrene. Presence of such complications reflects poor prognosis due to its association with delayed wound healing and increased risk of amputation (Beckert et al., 2006; Abbot et al., 2002; Boulton et al., 2008). Comparatively, lesser 
degree lesions like Wagner 1 and 2 lesions have a satisfactory outcome.

There was no statistically significant deference between the number of patients having combined Wagner 1 or 2 lesions and combined Wagner 3 or 4 lesions $(p=0.11)$. A survey done in a tertiary care hospital in Pakistan with the participation of hundred patients, the prevalence of Wagner 2 was $25 \%$. It is well below the value of this study (40.6\%). The collective percentage of Wagner 3, 4 and 5 was $55 \%$ in the Pakistani study (Rooh-ulMuqim et al., 2003). In this study, the corresponding value was $42.1 \%$. Therefore it is possible to assume that more patients with less complicated wounds are treated in the Sri Lankan tertiary care setting.

Foot margins were affected in 29 patients $(31.87 \%)$ which was the commonest location (Table 3). Pressure points such as heel, metatarsal heads were affected in 40 patients (43.95\%). This location is typical for neuropathic ulcers because it is the pressure bearing area in the foot. In that context, the prevalence of neuropathic lesions in this study should have been around 44\%. This assumption is arbitrary as neuropathy should be assessed by proper neurological tests with the aid of $5.07 \mathrm{~N}$ monofilament test, vibration assessment by $128 \mathrm{~Hz}$ tuning folk, temperature sensation and joint position sensation (Pham, et al., 2000). An assessment of that nature was beyond the scope of this study.

According to a survey done in a tertiary care hospital setting in Europe, 55\% of lesions were involving toes (Prompers et al., 2007). In comparison, only 39 patients in this study were having toe lesions $(42.85 \%)$. Heel was involved in $10 \%$ in the European study whereas it was $23.34 \%$ in this study. The exact reason for higher prevalence of heel lesion in this study is unknown although not wearing proper footwear has an important role to play. This is because, walking barefoot is an independent risk factor for the development of diabetic foot ulcers
(Jayasinghe et al., 2007). Whether this risk is confined to the development of foot ulcer in a particular location of the foot is not yet established.

Out of 55 males, 38 were either exsmokers or continued smoking at the time of admission (69.09\%). According to table 5, the lowest median pack year was associated with Wagner grade 2 lesions. In Wagner 1, 3 and 4, the median pack years was 5. No statistically significant difference was found between the cigarette smoking pack years and the severity of the lesion $(p=0.82)$.

Many studies are available in the literature assessing the relationship between smoking and diabetic foot ulcer formation. Although some of them show a significant association between these two factors (Moss et al., 1992) many studies have proven otherwise (Boyko et al., 1999; Abbot, et al., 2002; Kästenbauer et al., 2001). But not a single study has assessed how the severity of smoking results in foot ulcers of various degrees. Although the pathophysiology of smoking supports the dictum more smoking causes bad ulcers, this study has failed to show a significant association between these two factors. Infact, an inverse relationship was observed (Spearman rank coefficience $=$ 0.037). One main reason for this must be that significant proportion of this cohort was represented by ex-smokers. It is not entirely correct to assume that pathophysiological mechanisms of smoking act in the same way in patients who has given up smoking. On the other hand, patients tend to grossly under estimate their smoking habits during data collection. As a result, the real value of smoking pack years ought to be much greater than the observed value.

Association between the bony deformities and ulcer location is given in table 6. Since the study population was small, claw toe and hammer toe was combined to a single entity known as toe deformities. Similarly flat 
foot and rocker bottom feet were also combined. Frequency of lesions occurring in toes in patients with toe deformities were significantly higher than lesions occurring in other regions in the foot $(p=0.0185)$. Flat feet occur when the foot arches collapse due to body weight when the integrity of the bones, joints and ligaments are lost (Levy \& Valabhji, 2008). The pressure distribution in the feet is variable according to the degree of flat foot. Study revealed that higher number of lesions are scattered around fingertips and its margins of the foot than rest of the areas although a statistical significance was not observed ( $p=$ $0.0511)$.

\section{CONCLUSION}

Wagner classification is a time saving, easy to use diabetic wound classification system in a resource limited setting. Majority of patients in hospital setting has Wagner grade 2 lesions. There is no statistically significant difference between the number of patients having severe lesions (Wagner 3 and 4 ) and less severe lesions (Wagner 1 and 2). No statistically significant relationship is found between the pack years of smoking and severity of the foot lesions among cigarette smoking males. To get a more refined result, a larger sample size with active smokers should be enrolled. There is a statistically significant association between toe deformities (claw toe and hammer toe) and ulcer location concentrated to toes. This finding can be used for the production of unloading footwear for diabetes patients with toe deformities.

\section{REFERENCES}

ABBOTT C, CARRINGTON L, ASHE H, BATH S, EVERY LC \& GRIFFITHS J. The North-West Diabetes Foot Care Study: incidence of and risk factors for new diabetic foot ulceration in a community-based patient cohort. Diabet Med. 2002;19(5):377-84.
ARMSTRONG DG, LAVERY LA \& HARKLESS LB. Validation of a Diabetic Wound Classification System. Diabetes Care. 1998 May;21(5):855-9.

BECKERT S, WITTE M, WICKE C, KÖNIGSRAINER A \& COERPER S. A New Wound based Severity Score for Diabetic Foot Ulcers: A prospective Library (Lond). 2006 May.

BOULTON AJM, ARMSTRONG DG, ALBERT SF, FRYKBERG RG, HELLMAN R \& KIRKMAN MS. Comprehensive foot examination and risk assessment. Diabetes Care. 2008;31(8):1679-85.

BOYKO EJ, AHRONI JH, STENSEL V, FORSBERG RC, DAVIGNON DR \& SMITH DG. A prospective study of risk factors for diabetic foot ulcer. The Seattle Diabetic Foot Study. Diabetes Care. 1999;22(7):1036-42.

DINH T, VEVES A. The Influence of Gender as a Risk Factor in Diabetic Foot Ulceration. Wounds. 2008;20(6).

FERNANDO DJ. The prevalence of neuropathic foot ulceration in Sri Lankan diabetes patients. Ceylon Med J. 1996;41:96-8.

GRAYSON ML, GIBBONS GW, BALOGH K, LEVIN E, KARCHMER AW. Probing to bone in infected pedal ulcers. A clinical sign of underlying osteomyelitis in diabetic patients. JAMA. 1995;273(9):721-3.

HIATT WR. Medical treatment of peripheral arterial disease and claudication. N Eng J Med. 2001;(334):1608-21.

JAYASINGHE SA, ATUKORALA I, GUNETHILLEKE B, SIRIWARDENA V, HERATH SC, DE ABREW K. Is walking barefoot a risk factor for diabetic foot disease in developing countries? Rural Remote Health. 2007;7(2):692. 
JINADASA CVM, JEEWANTHA M. A study to determine the knowledge and practice of foot care in patients with chronic diabetic ulcer. Int $\mathbf{J}$ Collab Res Intern Med Public Heal. 2011;3(1):115-22.

KÄSTENBAUER T, SAUSENG S, SOKOL G, AUINGER M, IRSIGLER K. A prospective study of predictors for foot ulceration in type 2 diabetes. J Am Podiatr Med Assoc. 2001;91(7):343-50.

KATULANDA P, CONSTANTINE GR, MAHESH JG, SHERIFF R, SENEVIRATNE RDA, WIJERATNE S. Prevalence and projections of diabetes and pre-diabetes in adults in Sri Lanka-Sri Lanka Diabetes, Cardiovascular Study (SLDCS). Diabet Med 2008;25(9):1062-9.

KATULANDA P, SHERIFF MHR, MATTHEWS DR. The diabetes epidemic in Sri Lanka - a growing problem. Ceylon Med J. 2006;51(1):26-8.

LEDOUX, WILLIAM R. Relationship between foot type, foot deformity, and ulcer occurrence in the high-risk diabetic foot. Journal of rehabilitation research and development 42.5 (2005): 665-672.

LEESE G, SCHOFIELD C, MCMURRAY B, LIBBY G. Scottish Foot Ulcer Risk Score Predicts Foot Ulcer Healing in a Regional Specifications 2007.

LEVY MJ, VALABHJI J. The diabetic foot. Surg. 2008;26(1):25-8.

MOSS SE, KLEIN R, KLEIN BE. The prevalence and incidence of lower extremity amputation in a diabetic population. Arch Intern Med. 1992;152(3):610-6.

MUELLER MJ, MINOR SD, DIAMOND JE, BLAIR VPI. Relationship of Foot Deformity to Ulcer Location in Patients with Diabetes Mellitus. Phys Ther. 1990;70(6):356-62.
OYIBO SO, JUDE EB, TARAWNEH I, NGUYEN HC, HARKLESS LB, BOULTON AJM. A Comparison of Two Diabetic Foot Ulcer Classification Systems: The Wagner and the University of Texas wound classification systems. Diabetes Care. 2001;24(1):84-8.

PHAM H, ARMSTRONG DG, HARVEY C, HARKLESS LB, GIURINI JM, VEVES A. Screening techniques to identify people at high risk for diabetic foot ulceration: a prospective multicenter trial. Diabetes Care. 2000;23(5):606-11.

PROMPERS L, HUIJBERTS M, APELQVIST J, JUDE E, PIAGGESI A, BAKKER K. High prevalence of ischaemia, infection and serious comorbidity in patients with diabetic foot disease in Europe. Baseline results from the Eurodiale study. Diabetologia. 2007;50(1):1825.

ROOH-UL-MUQIM SG MA. Evaluation and management of diabetic foot according to Wagner's classification - A study of 100 cases. JAMC. 2003;3(15):39-42.

SENANAYAKE W, SAMARASEKERA L, FERANDO R, WEERAWARDENA WK. Bacterial characteristics and their antibiotic sensitivity pattern in Sri Lankan diabetic foot ulcers. Anuradhapura Med J. 2013;5(1):7-12.

SINGH, NALINI, DAVID G. ARMSTRONG, AND BENJAMIN A. Lipsky. Preventing foot ulcers in patients with diabetes. JAMA 293.2 (2005): 217-228.

SIRIWARDANA HDRC, WEERASEKERA D. The cost of diabetic foot conditions. Ceylon Med J. 2009;52(3):89-91.

SRIYANI KA, WASALATHANTHRI S, HETTIARACHCHI P, PRATHAPAN S. Predictors of diabetic foot and leg ulcers in a developing country with a rapid increase in the prevalence of diabetes mellitus. Public Library of Science; 2013;8(11):e80856. 
ULBRECHT JS, CAVANAGH PR, CAPUTO GM. Foot problems in diabetes: an overview. Clin Infect Dis. 2004;39 Suppl 2:S73-82.

VINCENT LR, ROMESH KHARDORI. Diabetic Ulcers Clinical Presentation. Available from:

http://emedicine.medscape.com/article/460282clinical\#b3 (Accessed on 30 June 2015).

WAGNER FW. The dysvascular foot: a system for diagnosis and treatment. Foot Ankle. 1981;2(2):64-122.

KANNEL WB . Risk factors for atherosclerotic cardiovascular outcomes in different arterial territories. J Cardiovasc risk. 1994;1:3333-9.

WEERASURIYA N, SIRIBADDANA S, WIJEWEERA I, DISSANAYEKA A, WIJESEKERA J, FERNANDO DJ. The prevalence of peripheral neuropathy in newly diagnosed patients with non-insulin-dependent diabetes mellitus. Ceylon Med J. 1998;43(1):19-21.

WHO - 10 facts about diabetes. World Health Organization; Available from: http://www.who. int/features/factfiles/diabetes/ee/ (Accessed on 30 June 2015). 